\title{
O ZUMBI NO IMAGINÁRIO MEDIÁTICO: Zumbi e Pulsão de Morte na Sociedade Mediática
}

Malena Segura Contrera

Universidade Paulista de São Paulo, São Paulo, São Paulo, Brasil.

\section{Leonardo Torres}

Universidade Paulista de São Paulo, São Paulo, São Paulo, Brasil.

\section{Resumo}

O artigo tem como objeto a irrupção simbólica nos meios de comunicação eletrônicos da figura do zumbi e tem como objetivo analisar o que ela representa no imaginário cultural e mediático. A pergunta que propõe é a de se o zumbi seria metáfora de alguma questão humana atual. Como método, mapeamos a recorrência do zumbi por meio de dados quantitativos do Google Trends. A partir disso, realizamos análise qualitativa de produtos mediáticos (seriados, filmes, jogos e notícias), afim de evidenciar o contexto cultural no qual o zumbi se manifesta simbolicamente. A discussão teórica proposta utilizou as contribuições de E. Morin, G. Durand, A. T. Portanova Barros, C. G. Jung e J. Gonzalo.

\section{Palavras-chave}

Imaginário Mediático. Morte. Zumbi.

\section{Introdução}

Este artigo situa-se no campo dos estudos da mídia e do imaginário, partindo do paradigma do Método da Complexidade de Edgar Morin e dialogando com algumas proposições teóricas da Psicologia Analítica de Carl Gustav Jung. O problema que motiva este estudo pode ser representado por uma experiência típica do dia a dia dos ambientes das grandes cidades, nas quais se pode sentir o que é "ser levado pela multidão", caminhar junto, em contágio (con-juntos; aggio - ação), ou seja, agindo em conjunto, na mesma direção.

Esse fenômeno torna-se mais consciente quando se erra o trajeto e encontra-se em direção oposta à da multidão - a vertigem de caminhar contra ela. Essa cena, para muitos indivíduos, é diária. E, também, no transporte público no caminho para o trabalho, 
muitas vezes os pensamentos não estão naquele momento, mas nas redes sociais digitais, na música que se está ouvindo, no calendário que se deve seguir, ou então em algum outro lugar qualquer. Porém, este fenômeno que está presente nos caminhos subterrâneos do metrô, nas calçadas e ruas de uma cidade grande com intenso tráfego, também pode ser observado dentro dos lares contemporâneos, nos quais os moradores permitem-se ser arrastados pelas programações televisivas ou pelas telas dos aparatos digitais em rede.

Compreende-se isso ao se considerar, por exemplo, dados como os trazidos por Meeker $(2017)^{2}$, que afirma que um homem comum estadunidense passa 5.6 horas diárias diante de mídias digitais. Já no Brasil, o IBOPE ${ }^{3}$ (2016) divulgou uma pesquisa de consumo de mídia pelo brasileiro, que revela que um cidadão médio costuma ficar 3,5 horas por dia assistindo à televisão e 4,6 horas por dia navegando na internet; cerca de 1/6 do dia de um indivíduo é diante das telas. É por meio delas que ele trabalha, comunica-se etc. Na arte, este consumo já foi apontado, por exemplo, por Steve Cutts, que aproxima o uso dos aparatos com a figura do zumbi ou a uma condição zumbizógena.
Partindo desse cenário social, a pergunta central que nos colocamos é: existe alguma figura do Imaginário Cultural que representaria o perambular, o "estar sem presença" (mas estar on-line) e essa ação em conjunto descrita acima? E que estaria irrompendo no contexto da sociedade contemporânea, revelando algo sobre o movimento atual dos campos do imaginário?

A hipótese sugerida é de que o zumbi é essa figura, e que ele, por meio do Imaginário, tem apontado para uma condição zumbizógena humana (do cambalear, da "sem presença", do contágio). Nossa hipótese principal é a de que esse estado de "viver sem corpo" ou, ao menos, de estarmos onde não está o nosso corpo tem gerado o oposto da apregoada vida plena; estamos vivendo a ação de uma intensa pulsão de morte. Nossa hipótese é de que estamos sob as asas de Thanatos.

O método de investigação do trabalho foi a realização de um levantamento de dados em que o zumbi foi a figura principal. Focou-se em diversos meios de comunicação social, como em filmes e séries zumbis de sucesso, abrangendo o ano de 1932 até 2017; games premiados, de 1996 a 2017; notícias que têm 
o zumbi como tema principal e curiosamente verídico; e produções mediáticas que revelam grupos de interação que têm se preparado para um iminente apocalipse, alguns deles, apocalipse zumbi. Além disso, utilizou-se da plataforma de pesquisa Google Trends, afim de evidenciar e comparar a figura do zumbi com outra de temática "morto-vivo", a do vampiro, revelando a intensidade e a recorrência da figura do zumbi nos últimos 14 anos.

\section{Figura 1: Steve Cutts e o Estado Zumbizógeno}

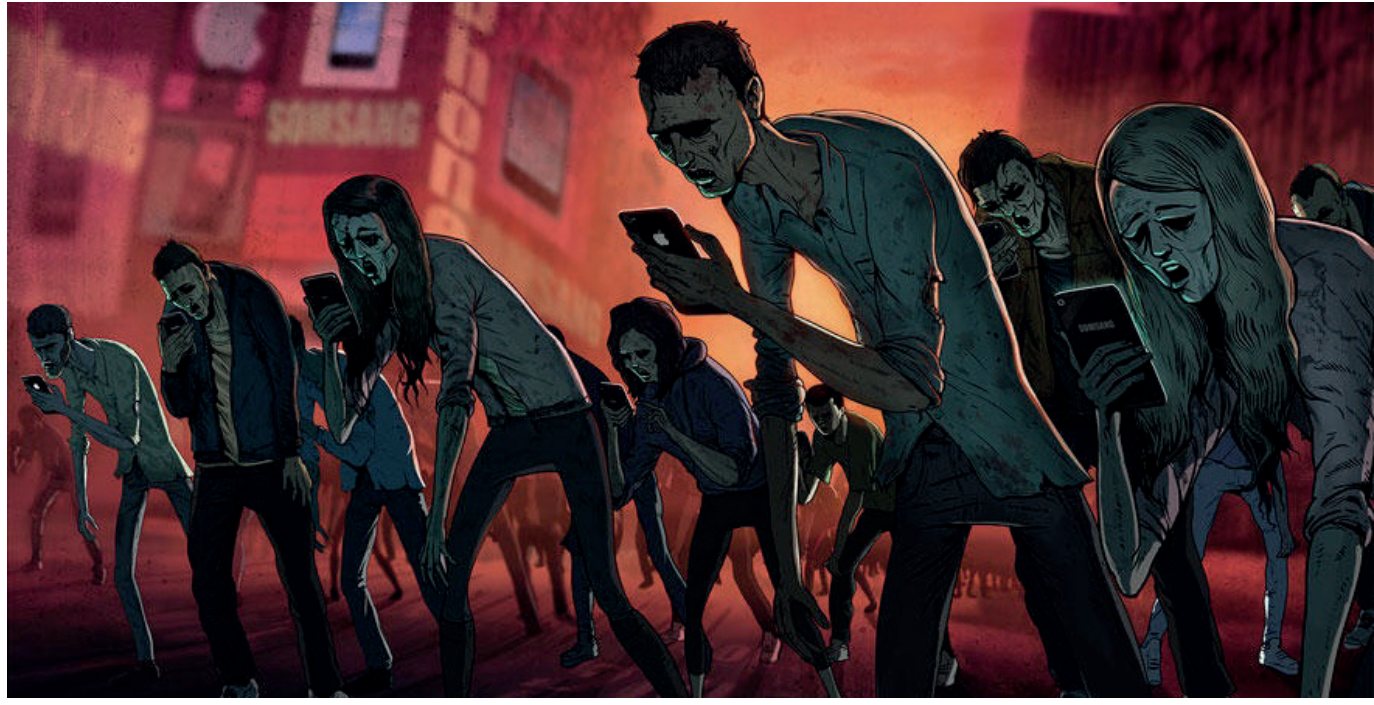

Fonte: Steve Cutts $(2017)^{4}$

Como não se trata da análise de um veículo específico, mas sim da irrupção simbólica da figura do zumbi, julga-se que o método deve contemplar e investigar a manifestação dessa figura em vários canais, apontando para a mobilidade do que Gilbert Durand nomeia como "Bacia Semântica"5. Neste sentido, o cuidado que se teve foi delimitar o período

Stevecutts. <http://www.stevecutts.com/> Acessado em: 22 de nov. 2017.

5 Durand (1996) mostra como uma sociedade tem seus níveis institucional (o das regras, dos programas, das pedagogias, das utopias...), actancial (onde se movem os atores sociais, com papéis positivos, aprovados pela ideologia em jogo, e papéis negativos, marginalizados, dissidentes) e fundador (o do inconsciente coletivo cultural e natural) animados por um mito diretor mais ou menos degradado, segundo a fase da bacia semântica em que se encontra, enquanto um outro mito, pleno de vigor subversivo, aguarda, no subsolo antropológico, o momento de emergir. (BARROS, 2014, p.153). 
temporal supracitado (14 anos) para a análise da irrupção simbólica da figura do zumbi.

\section{Aparição Zumbi nos Produtos Mediáticos}

Desde o lançamento do game Resident Evil para o console Playstation, no ano de 1996, foram produzidos incontáveis games de temática zumbi. Dentre eles, cinco destes jogos $^{6}$, especificamente de zumbis, foram considerados jogos do ano, isto é, o melhor e mais premiado jogo do $\mathrm{ano}^{7}$. São eles: Resident Evil 4 (2005), com 35 prêmios; Mass Effect (2010), com 101 prêmios; The Walking Dead (2012), com 75 prêmios; The Last Of Us (2013), com 249 prêmios; Doom (2016), com 29 prêmios.

A pesquisa sobre o mercado de games da Newzoo (2016) ${ }^{8}$ aponta que a indústria game gerou uma renda de 99,6 bilhões de dólares no ano de 2016, crescendo cerca de $13 \%$ desde o ano anterior. Esse dado é relevante, pois nesse mesmo ano, a Steam - plataforma de jogos para computadores pessoais - divulgou os 100 jogos mais vendidos, e, dentre eles, sete são categorizados pela própria plataforma como games de zumbis ${ }^{9}$. Portanto, a figura do zumbi também contribuiu para o crescimento dessa indústria.

A quantidade de filmes produzidos de temática zumbi também é volumosa. Dendle (2001) lista os filmes de zumbis de 1932 a 1998; no gráfico na página seguinte pode-se ver sua pesquisa.

Além disso, Dendle (2001) demonstra que, em um primeiro momento, o zumbi foi unicamente utilizado em filmes do gênero de terror, porém, hoje, a figura do zumbi também está presente em outros gêneros cinematográficos e abrangendo, dedutivamente, variados perfis de indivíduos. Por exemplo, a figura ainda está presente nos filmes de terror: Madrugada dos Mortos; Guerra Mundial Z; Eu Sou A Lenda; etc. Mas também, de acordo com o autor e com Smith (2018), ela está presente nos de comédia e de comédia romântica: Zumbilândia 1

6 Disponível em: <http://bit.ly/2A0NNVj> Acessado em 22 nov. 2017.

7 Idem.; 0 jogo do ano é julgado por vários portais especialistas em jogos, dentre eles: 1UP.com; Academy of Interactive Arts \& Sciences; Academy of Video Games; Baixaki Jogos; Crispy Gamer; Edge; Electronic Gaming Monthly; Eurogamer; Gamasutra; Game Informer; Game Pro; Games; Games Master; Game Rankings; Game Spot; Game Spy; Game Trailers; Giant Bomb; IGN; Joystiq; Kotaku; Los Angeles Times; Metacritic; New York Times; Spike Video Game Awards; The Game Awards; Time; X-Play.

8 Disponível em: <http://bit.ly/2cD62XZ> Acessado em: 06 dez. 2017. 
e 2; Todo Mundo Quase Morto; Meu Namorado é um Zumbi etc. E ainda em filmes infantis, como Para Norman. Portanto, o zumbi migrou de um gênero menos palatável para gêneros mais palatáveis, apontando para o fato de que a figura do zumbi estaria cada vez mais se banalizando, tornando-se cotidiana.

Gráfico 1: Filmes de zumbi entre 1932 a 1994.

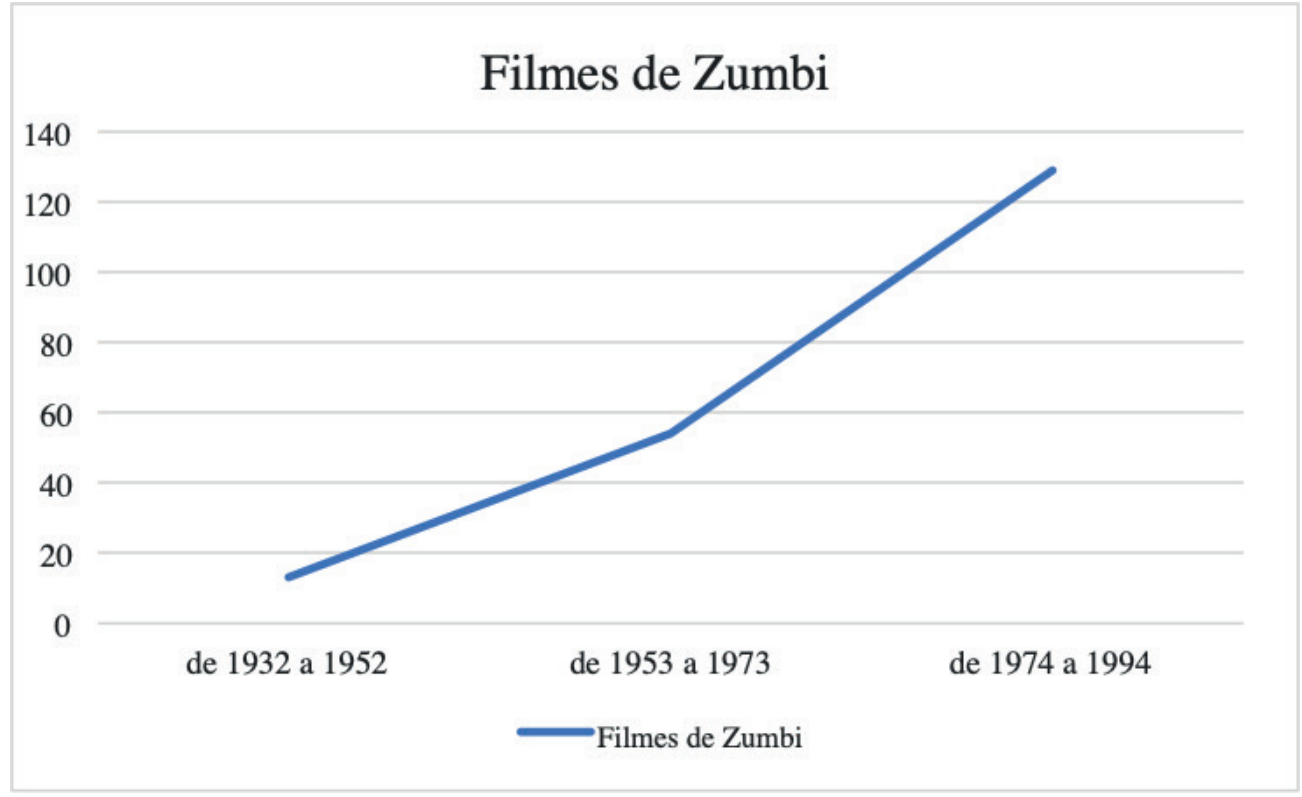

Fonte: Dendle (2001).

Financeiramente, a indústria de filmes de zumbis é extremamente rentável. A franquia de seis filmes de Resident Evil, por exemplo, rendeu 951 milhões de dólares em bilheteria ${ }^{10}$.

Apesar de ser uma das últimas a aderir à figura do zumbi, a literatura também o fez. Drezner (2011) também aponta que o número de produtos literários de temática zumbi quadruplicou na década de 2000 a 2010. Ao longo da última década, os zumbis também penetraram na literatura, que varia entre manuais de sobrevivência, livros infantis até romance vitoriano. Há também séries de quadrinhos como The Walking Dead e Marvel Zombies, que se 
espalharam rapidamente no mundo, nos últimos cinco anos (DREZNER, 2011, p. 16).

Surpreende que, além das ficções supracitadas, a figura do zumbi também apareça nas produções jornalísticas da internet. Existem notícias que descrevem casos de indivíduos que se tornaram aparentemente "zumbis" ${ }^{\prime}$. Sendo verídico ou não, atenta-se para a dimensão da presença do imaginário acerca do zumbi na notícia. Conforme Wade Davis (1987) e o portal Noite sinistra ${ }^{12}$, no ano de 1936, uma mulher com andar cambaleante foi encontrada em Porto Príncipe, no Haiti. Ela foi levada às pressas para o hospital em busca de ajuda, e lá os médicos perceberam que ela era surda, muda e cega, respondia somente por reflexos e movimentava a cabeça freneticamente. Os profissionais do hospital tentaram incessantemente localizar algum conhecido de sua família. Quando encontraram, seu marido e seu irmão passaram por um teste de reconhecimento, porém, alegaram que ela havia morrido no ano de 1907 (29 anos antes). O médico responsável pelo caso explicou-o denominando a mulher como um "zumbi".

\section{Figura 2: Foto tirada da mulher "zumbi", no Haiti.}

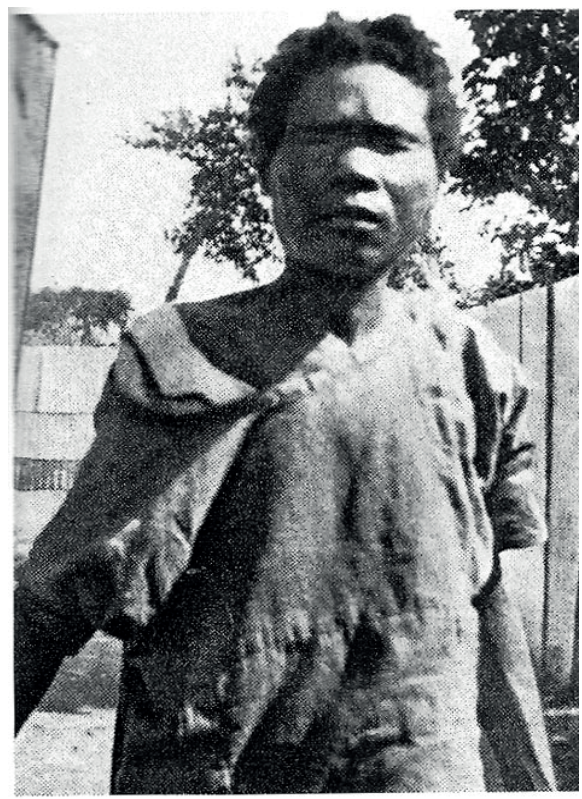

Fonte: Felicia $(2017)^{13}$

Atualmente, há crenças acerca de um iminente apocalipse zumbi na sociedade ocidental. Para ganhar popularidade ou não, na Columbia Britânica, província do Canadá, o Governo divulgou em seu portal BC Prepared, destinado às orientações para a população em casos de emergência, um manual de sobrevivência no caso de um iminente apocalipse zumbi ${ }^{14}$. Algumas dicas são:

12 Noitesinistra. Disponível em: <http://bit.ly/2uOHxKt> Acessado em: 06 jul. 2017.

13 Felicia. Disponível em: < http://bit.ly/2viSyED> Acessado em: 24 ago. 2017.

14 PreparedBC. Disponível em: <http://bit.ly/2B4zeS8 > Acessado em: 06 jul. 2017. E, também: EUAzumbi. <https://bit. ly/2yjJAwR> Acessado em: 13 jun. 2018. 
Dica \#1: Certifique-se de que o seu tanque de gás esteja sempre meio cheio. Dica \#2: Tenha kits de emergência para sua casa, escritório e carro. Dica \#3: tenha um plano! Dica \#4: Obtenha um kit de emergência. Dica \#5: tenha um contato fora da província. (BCPREPARED, 2017, on-line).

Chama a atenção que apareça no contexto do imaginário mediático, em mais de um caso, certa relação entre o contexto do apocalipse e a figura do zumbi, Sobre isso se pode destacar o estudo de Foster (2014),que discorre sobre os "Doomsday Preppers", um reality show americano exibido no National Geographic Channel de 2011 a 2014, que perfilava vários indivíduos denominados "preppers", os quais se preparam para sobreviver às mais variadas circunstâncias que podem causar o fim da civilização, incluindo colapso econômico, colapso social, pulso eletromagnético etc. Aqui o fenômeno não só ultrapassa a ficção como coloca indivíduos em um espetáculo com perigos reais para sobreviver ao iminente apocalipse.

\section{Zumbi e o Google Trends}

Além dos exemplos do fenômeno já supracitado, para identificar quantitativamente a recorrência da figura do zumbi, usou-se como a ferramenta de análise Google Trends ${ }^{15}$. Nela, é possível verificar a recorrência e a relevância relativa, em graus de o a 10, em pesquisas no Google da figura do zumbi e compará-la com outros termos pesquisados.

Foram utilizados, na modalidade "tópico de pesquisa", os termos "Zumbi", "Vampiro", devido às suas características de morto-vivo e suas divulgações nos meios de produção mediáticos ${ }^{16}$. Conforme o gráfico a seguir, o zumbi, em azul, substituiu a figura do vampiro, em vermelho, no quesito maior relevância de pesquisa. Especificamente, de 2004 a 2012 a relevância da figura do vampiro era superior à do zumbi. Depois de 2012, o zumbi passa a ser mais relevante (FIGURA 3).

Além da inversão, ainda é interessante observar que, em determinados momentos (mesmo mês), quando a figura do vampiro alcança seu ápice, a figura do zumbi também a acompanha e vice-versa. Poderia, então, tanto o zumbi quanto o vampiro serem movidos por um mesmo arquétipo? Ou melhor, seriam a transição e os ápices sincronizados evidências de uma irrupção de ordem imaginária?

15 Conforme a própria empresa Google: a ferramenta Google Trends permite analisar a evolução do número de pesquisas, ou seja, a relevância de uma palavra-chave ao longo do tempo. Existem pesquisas internacionais que já realizam pesquisas científicas com base no Google Trends (SEIFTER et al., 2010).

16 A figura do vampiro também é recorrente nas produções mediáticas. Um exemplo é o portal Filmow (2017) que reuniu 100 filmes desse tema. Disponível < http://bit.ly/2BL205c> Acessado em: 7 dez. 2017. 


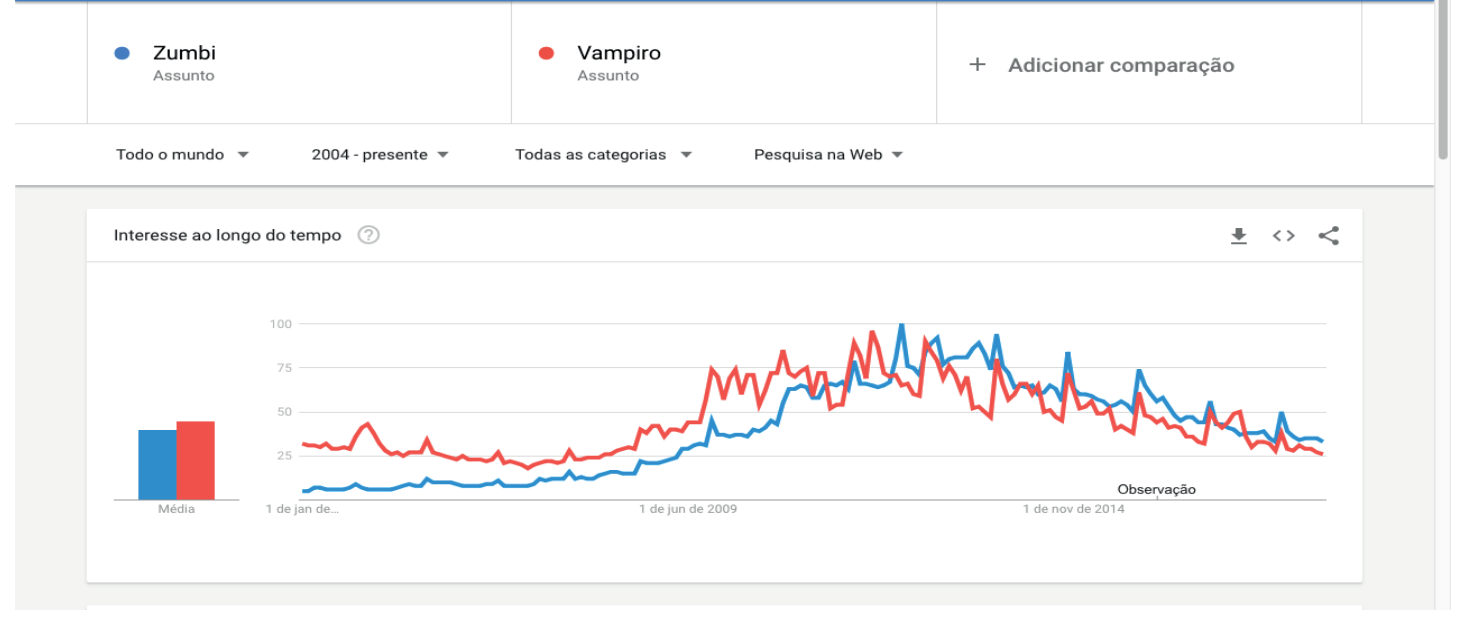

Fonte: GoogleTrends (2018).

Figura 4: Google Trends Zumbi-Vampiro

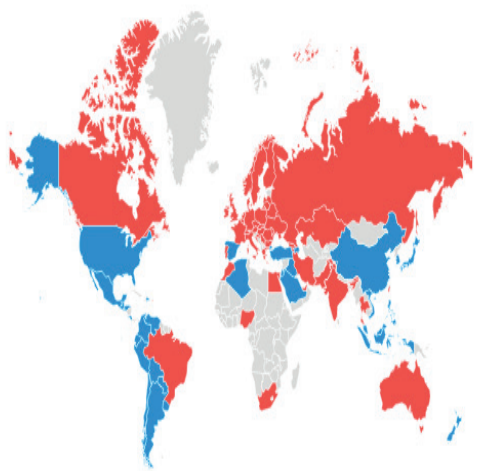

Fonte: Google Trends (2018). 
Ademais, no Google Trends, pesquisou-se também, na modalidade "tópicos", o termo "Morte" (FIGURA 5). O gráfico revelou um crescimento considerável nesse período comparado aos termos pesquisados acima, ou seja, indivíduos estão cada vez mais pesquisando o tema "morte" no Google. E, ainda, pode-se averiguar que, em alguns momentos, ocorre o mesmo sincronismo de ápices (mesmo mês) com as figuras acima pesquisadas. Parece tratar-se aqui de algo mais do que uma simples coincidência:

Figura 5: Google Trends Morte

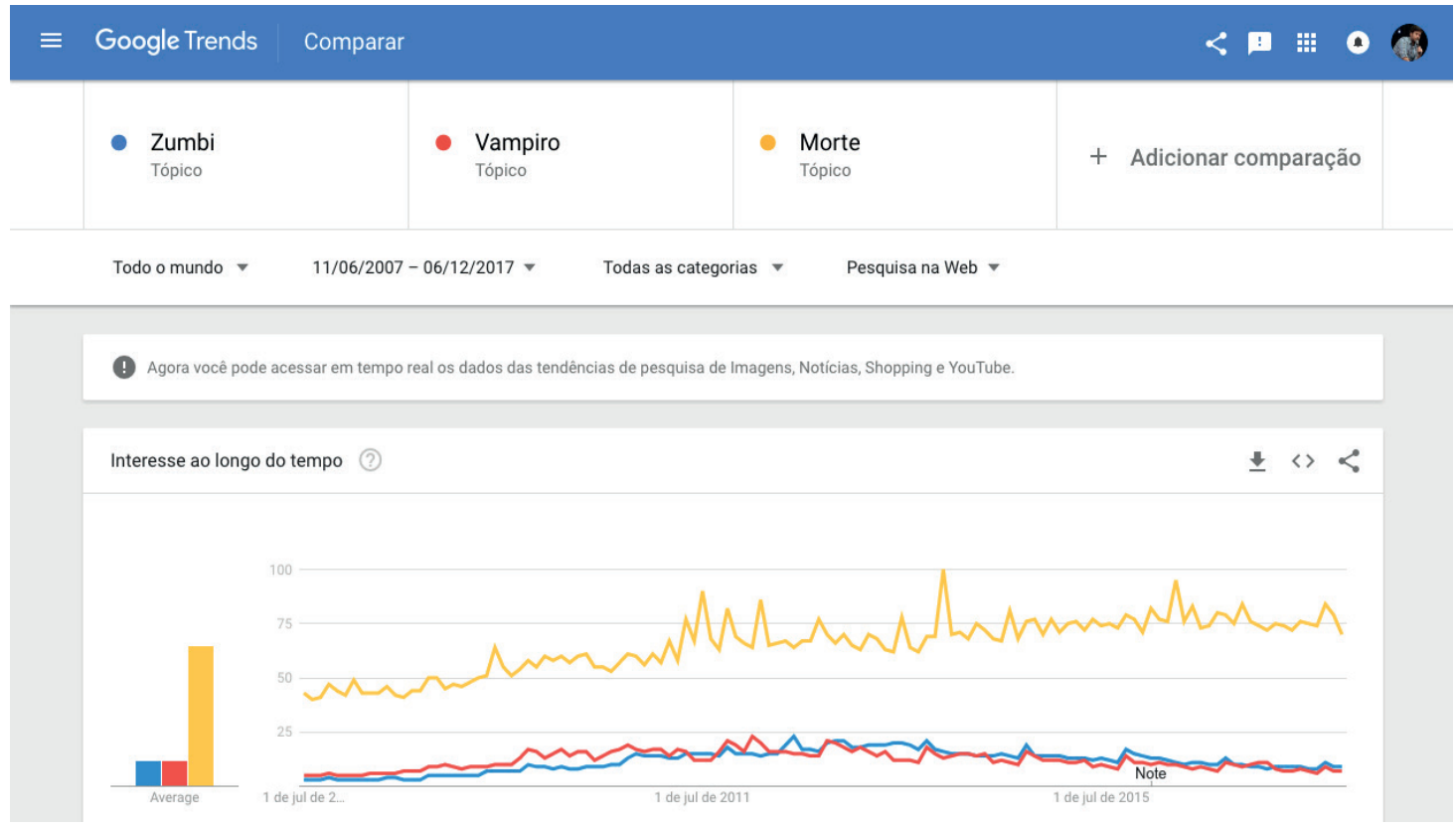

Fonte: Google Trends (2018).

Pode-se evidenciar, a partir desses dados (games, filmes, seriados, notícias, crenças e o Google Trends), que a figura do zumbi está presente na atualidade em diversas áreas da sociedade - produtos de massa; crenças e curiosidades; grupos radicais; na Biologia; entre outras. Além disso, vemos que o zumbi, tal como o vampiro, revela uma questão central que, apesar de não estar nele evidenciada, está em seu âmago: a Morte (e a tentativa de fugir dela). Seria a figura do zumbi - potencializada e recorrente nesta última década 
- um indício de "incêndio" da imagem da

Morte constelada ${ }^{17}$ no Imaginário Cultural?

\section{Sobre Zumbis}

O conceito exato do que é um zumbi ainda é bastante polêmico, mas podemos considerar algumas contribuições nesse sentido, como a do Urban Dictionary ${ }^{18}$, que propõe uma definição a partir do entendimento de que o zumbi seja um ser humano morto que retornou parcialmente à vida devido a causas desconhecidas. Tudo muito impreciso, mas as precisões surgem ao descrever suas características funcionais:

0 cérebro retém as instalações básicas, nomeadamente a função motora bruta. Em seu estado quase insensato, não apreende restos de emoção, personalidade ou sensação de dor. Em casos raros, alguns dos reanimados têm atividades rotineiras pré-formadas de suas vidas passadas. Os corpos apodrecidos dos mortos-vivos operam em uma fração do nível em que nossos corpos normalmente funcionam. Os sistemas circulatório, respiratório e digestivo não são afetados pela reanimação. Respirar, engasgar e gemer são reflexivos, mas nenhum oxigênio é transportado pelo sangue. 0 sistema nervoso funciona principalmente no cérebro e no tronco encefálico. A recepção sensorial é mínima, na melhor das hipóteses, e aparentemente não é necessária na busca de presas (URBAN DICTIONARY, 2017, on-line, tradução nossa).

A partir da teoria do cérebro triuno de MacLean (1990), esse excerto aponta que tanto o cérebro límbico quanto o pré-frontal são sub-utilizados ou nada utilizados no estado zumbizógeno. Somente está ativa a parte cerebral que lida com a sobrevivência, o reptiliano ${ }^{19}$. Chama também a atenção o fato de que o imaginário cinematográfico apresente o zumbi como inicialmente alimentando-se exclusivamente de cérebros, e que, por outro lado, um tiro no cérebro seja a única forma de se matar um zumbi. É como se a morte só se efetivasse de fato a esse não vivo por meio de uma espécie de morte cerebral.

No que tange ao comportamento, o dicionário em questão analisa o zumbi e ressalta suas capacidades enquanto seres:

Os mortos-vivos são incapazes de cansaço e persistirão a qualquer custo. Eles até se

170 termo "Constelar" é utilizado a partir da teoria junguiana para designar uma configuração de movimento da energia psíquica na pisque individual ou coletiva, esta configuração e movimento provocam em um indivíduo ou grupo imagens, emoções e comportamentos. Em síntese, é a manifestação de um arquétipo.

18 Urbandic. Disponível em: <http://bit.ly/2tuJYCw> Acessado em: 06 jul. 2017.

190 cérebro reptiliano é "o eixo mais básico do sistema nervoso, composto de medula espinhal, tronco cerebral, cerebelo, diencéfalo e gânglios basais, responsáveis por comportamentos estereotipados geneticamente determinados e funções parassimpáticas (involuntárias)" (MOGRABI, 2005, p.228). 
arrastam quando suas pernas foram removidas. Mesmo que a cabeça seja removida do corpo, ela continuará a viver. [...] A única ação observável em que um zumbi participa é matar criaturas vivas, especialmente seres humanos, e comê-las. Muitas teorias e especulações envolvem este comportamento perturbador. Uma teoria baseia-se no pensamento de que a reanimação é o resultado de uma infecção ou vírus contagioso, e que o impulso primário para alimentar irá espalhar a doença para outros órgãos hospedeiros. [...] . Outra teoria é que os zumbis comem o cérebro dos vivos para reabastecer a "falta de vida" que dá serotonina química. [...] A especulação final parece a mais óbvia, que os mortos alimentam o sustento para saciar seu metabolismo não natural. [...] A criatura continua a comer mesmo depois que o intestino estava aberto. [...] Os zumbis tentarão comer quando seus estômagos e até os maxilares foram removidos. ${ }^{20}$ (URBANDICTIONARY, 2017, on-line, tradução nossa, grifo nosso).

Esta descrição, apesar de ampla, mostra como a figura do zumbi é vista na contemporaneidade. Em sentido mais estrito, o Oxford Dictionaires ${ }^{21}$ pontua que o zumbi é uma figura folclórica - provindo demitologias africanas e caribenhas - de um cadáver sem consciência revivido por um bokor (feiticeiro intermediário da mitologia voodoo). O termo foi inscrito pela primeira vez na linguagem
Kikongo, em 1819, designando "zumbi" como fetiche; e "nzambi" como uma divindade ligada à figura da serpente.

Segundo Handerson (2010), a crença zumbi provém do voodoo, mitologia surgida a partir de povos africanos que foram levados como escravos para o Haiti e outras partesdo Caribe, nos séculos 18 e 19. O voodoo foi uma forma de reafirmar a identidade desses povos no contexto novo do viver em terras novas (na América) e na escravidão. Porém, o que surgira como forma de resistência tornou-se mercadoria: o voodoo e o zumbi foram disseminados, espalhando-se pelos Estados Unidos da América e pela Europa e, enfim, cooptados pela Cultura de Massas.

Ainda sobre a mitologia haitiana, Handerson (2010), que estudou o voodoo e a figura do zumbi em sua dissertação de mestrado, aponta:

Os praticantes do Vodu acreditam na existência dos seres espirituais, que vivem em algum lugar no universo, estando completamente ligados e em comunhão com os seres humanos. Portanto, eles acreditam haver dois mundos: 0 celeste, no qual vivem os seres espirituais, isto é, as divindades; $\mathrm{e}$

20 Interessante observar que o déficit de serotonina - um neurotransmissor - é um dos vetores que levam a depressão, uma das patologias psíquicas que mais acomete a humanidade atualmente (CAPONI, 2009). 
o terrestre, em que estão os humanos, de carne e osso. Reconhecemos ser essa visão dicotômica uma influência de dualidade que não existia no universo dos cultos na África; essa visão aparece nos cultos no Novo Mundo, a partir da influência grega do catolicismo nesses cultos afro-latino-americanos. (HANDERSON, 2010. p.123, grifo nosso).

A ideia platônica da dualidade acima exposta nas mitologias voodoo, cristã etc. corrobora especialmente com a questão do zumbi, pois a dualidade matéria/alma permite a crença de um bokor (feiticeiro menor) inserir uma alma estranha a um cadáver, tornando-o um morto-vivo, assim como o próprio autor discorre:

Isso acontece quando o bokor - aquele que faz de suas habilidades em relação aos elementos do Vodu um comércio e um meio de fazer mal ao próximo - é consultado pelas pessoas para fazer magia de modo negativo a fim de atingir outra pessoa e usa o conhecimento das folhas, das plantas medicinais na prática de magia, a qual pode deixar uma pessoa num estado de letargia ${ }^{22}$, isto é, sonolência profunda e prolongada. Essa pessoa, ao chegar a esse estado, é vista como um morto pela sua família, porque é quase impossível distinguir o estado de letargia da morte. (HANDERSON, 2010, p.137, grifo nosso).
Uma breve analogia já levanta a questão sobre a falta de consciência de si - a letargia - da mitologia voodoo e o perambular, a "não-presença" e o contágio vistos nos ambientes das grandes cidades contemporâneas atravessadas pela onipresença das tecnologias da comunicação de que falávamos no início deste texto. E se há uma tênue diferença entre letargia e morte, o que significaria o estado letárgico, que poderíamos aproximar dessa "quase-morte", de tantos indivíduos na sociedade contemporânea?

Oestadoletárgico, por sua vez, é muito útil para o bokor devido à facilidade de manipulação:

Depois de tomá-lo, ele fica num estado de idiotice, obedece a tudo que o mandam fazer. [...]. Geralmente no meio rural, o dono do zombi explora-o, forçando-o a trabalhar no seu rebanho (HANDERSON, 2010, p.138, grifo nosso).

Em “O Trabalho como Vida”, Kamper (1998) já aponta para uma mortificação do corpo e para o tratamento do corpo como algo explorado e forçado a trabalhar cotidianamente. O processo de industrialização do mundo, como apontou E. Morin, ao tratar sobre a cultura de massas do século $\mathrm{XX}$, gerou um trabalho mecânico que afeta 
o corpo humano. Há aí, portanto, um corpo mortificado, e não por acaso Morin traz nos subtítulos dessa obra a noção de que caminhamos da neurose para a necrose.

Gonzalo (2011), em "Filosofía Zombi", desenvolve uma pesquisa documental focada em uma crítica do modus operandi social e na mídia eletrônica. Seu ensaio aponta que o ser humano contemporâneo, usuário dos meios eletrônicos, serve sem questionar às intenções do sistema capitalista. Este último, por ter entre seus aspectos a lei da oferta e da demanda, gera, descontroladamente, o "consumo zumbi", ou seja, um consumo desenfreado e inconsciente pelos indivíduos em prol de garantir o lucro das empresas, como as indústrias farmacêuticas, alimentícias, de entretenimento etc.

O andar constante do zumbi e sua eterna busca pela devoração dos cérebros não deixa de ser uma metáfora perfeita para esse modo de vida pautado pelo consumo nas sociedades capitalistas: ansiedade e compulsão, criadas para mover os lucros advindos do consumo, para em seguida serem tratadas com medicamentos que as controlam, promovendo assim mais consumo. No momento em que esse ciclo perde qualquer referência de seus limites, o consumo transforma-se no autoconsumo. Parece que o zumbi quer nos dizer que, nesse autoconsumo, a primeira coisa que devoramos em nós mesmos são os nossos cérebros.

Hillman (2016), criticando a dissociação entre corpo e alma, afirma que estamos desconectados com a alma do mundo (anima mundi) e diz que isso se fez acompanhar por uma tendência à literalização. À dimensão simbólica que se enfraquece, segue-se a literalização; em nosso caso, encara-se o zumbi como fato: jornais falam dele, manuais de sobrevivência governamentais ocupam-se de um ataque zumbi apocalíptico. Para o autor, essa literalização é um traço paranoico, pois a paranoia tende a literalizar conteúdos psíquicos, em vez de penetrar na sua profundidade simbólica, metafórica. Daí, passamos a converter conteúdos imaginários em casos concretos, como o apocalipse zumbi dos Doomsday Preppers.

Mortificado pelo trabalho, sedado pelas imagens mediáticas, alheio ao próprio corpo, mas faminto de consumo ininterrupto, pode-se conceber que o zumbi represente muito bem o homem contemporâneo, sem alma, ou, ao menos, sem ânimo.

Handerson (2010) afirma que, para livrarmo-nos do zumbi, ainda há uma saída:

Quando a pessoa se transforma em zombi, ela não vive como era antes, tem uma vida diferente das demais pessoas, ela come, dorme, compreende, até fala, mas de modo 
diferente, e o som sai do nariz (entonação nasal), mas ela não tem lembrança e não está consciente de seu estado. Por isso, é proibido dar comida salgada para um zombi, o sal desperta a consciência e provoca a sua revolta de parte. Já há muitos casos no Haiti de zombis que foram encontrados nas ruas das cidades. Familiares encontraram vivos seus seres queridos já enterrados por eles mesmos (HANDERSON, 2010, p.137, grifo nosso).

Outro aspecto que toma a atenção é a proibição do consumo de sal pelo zumbi. Platão $0^{23} \mathrm{diz}$ que "o sal é uma substância cara aos deuses". Daí, por exemplo, provém a palavra "salvação". No dicionário de símbolos de Gheerbrant e Chevalier (2017, p.767), o sal é apresentado como um elemento de incorruptibilidade: um protetor contra a corrosão (e putrefação) no cristianismo; purificador e protetor no xintoísmo; sabedoria na liturgia batismal. E, ainda, para os autores, os místicos ainda entendem a alma humana como uma terra salgada (fertilizada). Daí, o sal contra o zumbi, pois devolveria sua alma (ou sua consciência) ao corpo letárgico.

Comparando a figura do zumbi no entendimento amplo e estrito, entende-se que os zumbis são vistos como seres mortos-vivos de pouca ou nenhuma consciência. No entanto, há uma grande diferença entre como o zumbi se apresenta na mitologia voodoo e no cenário mediático. Na primeira, ele é visto como servo, como escravo, em estado letárgico, muito semelhante à própria escravidão vivida em épocas passadas; poderia aí, ser a figura do zumbi, um instrumento de compensação da mente humana para suportar o contexto infeliz da escravidão. Já na contemporaneidade, o zumbi apresenta-se em massa, mais animalesco, instintivo, ainda que letárgico, em bando e sedento para transmitir o vírus, a bactéria, o fungo etc. Cambaleante e lento no início, toma agilidade ao andar e perseguir suas vítimas no imaginário mediático. Ele deixa de ser escravo de um feiticeiro e passa a ser escravo de sua própria enfermidade parasitária. Ou, então, existe algum bokor que ainda não foi identificado na contemporaneidade que induz ao estado zumbizógeno? Seria ele a Mediosfera ${ }^{24}$ ?

O zumbi é um morto-vivo per si, ou seja, é um ser que está morto, mas, paradoxalmente, escapou da morte. Ao mesmo tempo, é um ser que se move, gesticula, por vezes fala; contudo, ao mesmo tempo, não vive, se 
considerarmos que, para o homem, a vida equivale à consciência. Então, ser um "morto-vivo", não significa ser morto e vivo, mas ser nem morto e nem vivo ao mesmo tempo. Ser nem morto nem vivo é ser reificado (e apodrecido). No caso, como um receptáculo. A magia lançada pelo bokor tende are(anima) r o corpo (reificado), isto é, dar uma alma estranha a ele. Essa alma é sintética, letárgica e totalmente manipulável.

\section{A Recorrência do Imaginário Cultural}

Para compreendermos o que temos chamado de Imaginário Cultural, recorremos às contribuições conceituais de Edgar Morin (2011), por meio da proposição da "Noosfera", e de Jung (2008 e 2011b), por meio da sua teoria acerca da natureza do Inconsciente Coletivo; em ambos encontramos ferramentas teóricas que nos ajudaram a pensar o processo pelo qual se constela um arquétipo no Imaginário, manifesto nas recorrências de motivos simbólicos nos meios de comunicação de massas e massivos. Não é o intuito deste artigo prolongar-se nesta discussão conceitual, já que tratamos longamente disso em outro momento (CONTRERA: 2017 E ARAÚJO; PORTANOVA; CONTRERA; ROCHA: 2018).
O Imaginário Cultural pode ser considerado sinônimo do que Edgar Morin (2011) aponta sobre a Noosfera - a esfera dos espíritos. Esta, por sua vez, possui certa autonomia em relação à psique individual. Nesta esfera estão enraizados deuses, mitos, crenças, ritos, isto é, todos os substratos da cultura humana (os arquétipos ${ }^{25}$ ). Esta é a esfera na qual o zumbi origina-se e à qual pertence.

Carl Gustav Jung mostrou, por meio de sua teoria como os arquétipos do Inconsciente Coletivo são capazes de constelar-se em, por exemplo, complexos psicológicos. Jung ainda afirma que os complexos podem ser tanto de ordem pessoal como de ordem coletiva, e podem eclodir à mente de um ou mais indivíduos intensa e recorrentemente. Essa afirmação fica evidente em "O Eu e o Inconsciente" (2011b), "O Homem e Seus Símbolos" (2008), "Respostas a Jó" (1986) e "Aion" (1982). Estes dois últimos são exemplares para nossa questão, pois Carl Gustav Jung discorre neles sobre o Apocalipse de João, tratando sobre como os processos do inconsciente coletivo constelam-se, gerando o que ele chamou por "corrente dos tempos". 
Pode-se também considerar, em contraparte, a emergência do Imaginário Cultural de uma forma mais estereotipada. Morin (1997) afirma que os seres de espíritos (mitos, ritos, deuses etc.) foram apropriados pelo sistema econômico e transformados em estereótipos: filmes, seriados, games, celebridades, espetáculos etc. Estes produtos mediáticos utilizam os seres de espíritos em prol do consumo e da geração de lucros. Contrera (2017) denomina esse fenômeno da apropriação do Imaginário Cultural por uma lógica tecno-instrumental e econômica dos meios de comunicação de Mediosfera, reconhecendo esse processo como criador de uma esfera própria dentro do Imaginário Cultural, um núcleo secundário, que vampiriza esse Imaginário Cultural (Noosfera) e transforma os seres de espírito em mercadorias, desvitalizadas de seu poder simbólico ${ }^{26}$.

Como supracitado, os arquétipos tendem a emergir conforme o passar do processo sócio-histórico e há recorrências deste arquétipo por meio de diferentes figuras. No caso deste trabalho, como visto, a plataforma do Google Trends apontou que há recorrência e alternância desses motivos simbólicos por meio dos termos de busca em grande parte dos usuários dos meios eletrônicos, sendo eles ainda sincronizados, atingindo o ápice juntos.

Esta ideia da recorrência já foi vislumbrada pelas teorias do Imaginário, como a de G. Durand (1982), ao tratar dos mitemas, ou melhor, do que ele designa por "Metáforas Obsessivas", por serem recorrentes e redundantes na cultura humana global. Para o autor, mitemas são descobertos a partir da mitocrítica, que consiste em examinar, por um largo período, os produtos (avatares, deuses, símbolos, crenças, mitos, rituais, artes, ideias etc.)apresentados em diversas áreas de uma sociedade. Essa análise revela um comportamento humano por detrás de todo o modus vivendi geográfico, cultural e histórico de uma sociedade (DURAND, 1982).

O que acreditamos ser interessante considerar é que o Imaginário Cultural, como autônomo, podendo ser percebido por meio dos símbolos presentes nas produções imaginárias de uma sociedade, está nos apresentando a constelação da figura do zumbi, apontando para o fato de que isso certamente revela algo específico acerca do homem contemporâneo. 


\section{Zumbi, o morto-vivo}

Davis (1987), em sua corajosa tese de doutorado em Harvard The Serpent and the Rainbow, que toma os zumbis como tema central, foi em busca de fatos concretos ligados atais criaturas em uma pesquisa de quatro anos no Haiti, sendo três in loco. Ele discorre sobre o fato de que os feiticeiros (bokors) utilizavam um veneno que faz um indivíduo parecer morto, mesmo que esteja vivo (DAVIS, 1987). Essa poção provém de uma toxina de um peixe (baiacu) misturada a ervas com poderes alucinógenos e partes humanas (ossos e pele). Davis (1987) afirma que ${ }^{27}$ :

“0 que minha pesquisa tenta sugerir não é que exista uma linha de produção de zumbis no Haiti, mas que o conceito se baseia em algo real", argumenta Davis [...]. "[Na lenda] um zumbi é alguém que teve sua alma roubada por um feitiço e que fica capturado em um estado de purgatório perpétuo e que acaba sendo mandado para trabalhar como escravo em plantações. Hoje sabemos que não há nenhum tipo de incentivo para criar uma força de escravos-zumbis no Haiti, mas dada a história colonial aliada à ideia de perder a sua alma - o que significa perder a possibilidade de ter uma morte digna para o voduísta -, tornar-se um zumbi é um destino pior do que a morte $(\mathrm{G} 1,2017$, on-line, grifo nosso).
Em síntese, as descobertas de Davis (1987) apontam para um núcleo simbólico que liga o zumbi à questão da perda da alma, tratando de um estado zumbizógeno morto-vivo que em tudo se assemelha a essa espécie de estar em sociedade, mas não estar presente, de que vimos falando acerca da sociedade mediática.

Difícil não comparar esse processo de "dar uma alma estranha" a um indivíduo viciado em crack ou ainda na droga krokodili ${ }^{28}$, drogas que vêm preocupando especialmente os setores de saúde: o primeiro pela expansão de seu uso; o segundo pelos efeitos deteriorantes (GUIMARÃEs, 2018). Culturalmente, o ato de soprar e também o de fumar (o inspirar e o expirar) nas culturas arcaicas era intrinsecamente relacionado ao de "espiritualizar" o corpo (JUNG, 1982 e 2012) e (ELIADE, 2002). Para as culturas arcaicas, utilizando químicas alucinógenas ou não, os rituais que envolviam inspirações e expirações tinham a finalidade de centralizar o "espírito" (pneuma) no próprio corpo do indivíduo, garantindo a alteridade e o papel do participante na comunidade. Nas culturas arcaicas, o contexto mítico tornava as substâncias químicas secundárias, meramente auxiliadoras, porém atualmente parece ter havido um deslocamento em que 
a substância química é a finalidade. Ficaram as drogas, e o sentido de inspirar/expirar já se perdeu, resultando somente na experiência de "uma alma estranha" em um corpo viciado em consumir ${ }^{29}$.

De acordo com Guimarães(2018) e sua pesquisa para a Universidade Estadual do Rio de Janeiro,

[...] o cérebro humano possui cerca de 100 bilhões de neurônios cada um com quase 10 mil conexões com outros neurônios, as chamadas sinapses, [biologicamente] isso é o que nos torna humanos e nos diferencia enormemente de outros primatas. Nas sinapses, a porta de comunicação entre os neurônios, ocorre a passagem do impulso nervoso mediante a liberação de uma substância química, o chamado neurotransmissor. Um neurotransmissor se destaca quando $o$ assunto é 0 abuso de drogas: a dopamina. [...]. Uma dessas regiões, muito rica em dopamina é a mesolímbica. Ali a dopamina é liberadaem resposta a situações como ao ingerirmos alimento ou num orgasmo. Por outro lado, na esquizofrenia, nessa região há um excesso de dopamina, e esse fenômeno explica os chamados sintomas positivos da esquizofrenia: alucinações, agitação motora, etc. Portanto, pode-se dizer que a via dopaminérgica (isto é, que libera dopamina) mesolímbica está envolvida nas sensações de prazer e motivação (GUIMARÃES, 2018, on-line).
Esse excerto revela que essa busca excessiva e radical pela dopamina se dá devido à falta de estímulos, obviamente não sintéticos (como as drogas), mas culturais, a saber: ingestão dos alimentos certos, orgasmos, estímulos aos sentidos de proximidade, motivação (relacionada às emoções, emovere). Ou seja, estamos falando de vivências que estiveram presentes em todas as culturas arcaicas do mundo (ELIADE, 2002), tais como a dança, a música e o ritmo presente nos rituais, e demais maneiras de apropriação do mundo pelo corpo. Considerou-se que as práticas culturais possuíam um papel sociabilizador, religioso, porém, pode-se considerar que elas também possuam um papel biológico, na medida em que sincronizam corpo e alma, ou mito e corpo, como prefere J. Campbell e S. Keleman (2001). A resposta de um monge Xintoísta a Campbell, quando o questiona sobre sua mitologia, resume a questão: "nós não temos ideologia. Nós não temos teologia. Nós dançamos" (CAMPBELL, 1990, p.13).

Em um mundo em que os indivíduos passam grande parte de seus dias no trabalho, em transportes lotados, atravessando (e não ficando em) praças depredadas, e utilizando parte do dia conectados a aparatos que somente "estimulam" dois de todos os 
outros sentidos do corpo, a saída mais fácil e rápida para se obter a dopamina nunca será o processo integral do resgate de vivências simbólicas, mas sim o consumo de drogas (LORENZ, 2009). A falta do processo de simbolização (a perda da alma) e a exacerbação das drogas apontam para a condição zumbizógena da sociedade (letargia, escravidão ao bokor, vício etc.).

\section{0 que o Zumbi diz Sobre Nós}

$\mathrm{Na}$ área das Ciências Sociais, Jorge Henrique Fugimoto ${ }^{30}$ desenvolveu uma análise das cinco primeiras temporadas da série The Walking Dead e intitulou o estudo de "Além da Tv: um estudo sobre a série The Walking Dead".

Esse subgênero do terror envolve criações pós-11 de setembro que estabelecem vínculos, de forma implícita, aos eventos que sucederam esse fato, expondo uma alta carga de violência, destruição do corpo e sangue. "Há um forte paralelo com as produções zumbis, em especial The Walking Dead, por representarem a ruptura da sociedade, despertando no público as fantasias de sobrevivência e os sentimentos de ansiedade e desconfiança”, analisa Fugimoto (UNIFESP, 2017, on-line).

Apesar do The Walking Dead servir também como objeto de estudo, a reflexão de Fugimoto sobre o zumbi é interessante para o escopo deste artigo. O autor liga o zumbi à pulsão de morte (violência, destruição e sangue) e ao pânico (sobrevivência, ansiedade e desconfiança). Aprofundamos esse assunto quando propusemos entender mais a fundo o fenômeno do pânico, relacionando-o à imagem primitiva da divindade Pan. A fuga da morte levou o ser humano para uma virtualização da vida:

\section{Com a distância, a virtualização, o homem perde a experiência do tempo presente, livra-se também, por outro lado, da cons- ciência da transitoriedade. A imagem virtual traz a ilusão da eternização de uma pessoa no momento mesmo em que, de fato, o que ocorre é a dissipação do sujeito corporal, de sua identidade concreta. [...] Ao abrirmos mão da morte, abrimos mão também da vida, já que elas são indissociáveis (CON- TRERA, 2002, p.54).}

Esse quase-desejo de morte, por via da busca da abstração do corpo, faz-nos ver pontos de contato entre o pânico e esse morto-vivo, nem vivo nem morto, que é o zumbi.

Foster (2014) também faz o mesmo ao estudar os acumuladores e os Doomsday Preppers. Segundo o autor, essa parte da sociedade vive em um estado de alerta, aterrorizado com o futuro, pois, para eles, o fim do mundo está próximo. Dessa forma, como supracitado, 
muitos se isolam da sociedade e formam subgrupos preparados para enfrentar o "Apocalipse". Seja no pânico ou no zumbi, o que está em crise são as capacidades atribuídas ao cérebro pré-frontal: reflexão, linguagem, simbolização.

A preocupação com a sobrevivência e a fixação na morte e no fim iminentes não são fenômenos somente atuais. A morte, sem dúvidas, é o grande tema, um tema antropológico por definição, e não podemos ignorar sua importância no surgimento da cultura, no que Morin (1979) chamou de caráter demens da espécie. Também Leroi-Gourhan (2007) mostrou-nos claramente como o maior espanto do ser humano foi a tomada de consciência da morte, e de que, a partir dessa consciência, vem a singularidade, ou seja, a experiência vital da idiossincrasia do espaço-tempo. As mitologias surgem a partir daí, e, em um processo de retroação, tentam dar sentido ao espanto do homem diante da morte.

Ao longo dos anos, os mitos foram se complexificando e tornaram-se mais elaborados; a própria morte foi considerada uma divindade, como na mitologia grega: "A morte é personificada por Tânatos, filho da Noite e irmão do Sono, arisco, insensível, impiedoso (LAVD, 656-664) (CHEVALIER E GHEERBRANT, 2017, p.621-623). Ou ainda ricamente simbolizada por animais, figuras lendárias, rituais, objetos:

$\mathrm{Na}$ iconografia antiga, a morte é representada por um túmulo; um personagem armado com foice; uma divindade com um ser humano entre as mandíbulas; um gênio alado; dois jovens, um negro, 0 outro branco; um cavaleiro; um esqueleto; uma dança macabra; uma serpente ou qualquer outro animal psicopompo (cavalo, cachorro etc.) (Idem).

Já na tradição alquímica há um indício muito pertinente da figura do zumbi na palavra "putrefação":

Para os Hermetistas, é a principal das operações químicas [...] é a morte dos corpos e a divisão das matérias de nosso composto que as leva à corrupção e as dispõe à geração. A putrefação é o efeito do calor dos corpos mantido continuamente, e não de um calor aplicado manualmente. É preciso, portanto, ter-se o cuidado de não deixar que o calor excitante e exterior ultrapasse uma temperatura temperada: a matéria reduzir-se-ia à cinza seca e vermelha, em lugar do negro, e tudo pereceria (PERD, 418-419). Apodrecer, se é que se pode dizer assim, com o tempo e medida, e não se evaporar em um átimo. [...] Putrefação significa, mais geralmente, de acordo com a etimologia da palavra, cair na podridão. Mas o simbolismo é o mesmo: da morte ao renascimento a uma outra vida (CHEVALIER E GHEERBRANT, 2017, p. 748-749, Grifo do Autor). 
Também no hino homérico há uma referência à origem dessa forma de envenenamento que leva à putrefação:

Outro exemplo desse simbolismo da putrefação nos é dado pela lenda do monstro Píton (Pitão), morto pela flecha de Apolo. [...] Píton, enquanto monstro, provinha da terra e dava oráculos; era um animal ctônico. Ao destruí-lo e ao substituir-lhe o oráculo, Apolo, que é origem uraniana, assegurava a vitória do céu sobre a terra. A putrefação do monstro era a condição do triunfo de Apolo, ao mesmo tempo que o efeito da ação do Sol, sendo a flecha, por seu lado, o símbolo do raio solar. Daí em diante, não era mais dos antros da terra, mas do céu dos Delfos, que viriam os oráculos.

Desde a mitologia grega, percebe-se, por meio dos mitos, a tendência ocidental de desvalorizar o corpo (a terra, o concreto), e entendê-lo como putrefável, perecível, eis a aspiração humana pela imortalidade. O trecho acima revela uma tendência à supervalorização do espírito humano em detrimento do corpo; isso é recorrente tanto em Platão quanto no Cristianismo, e também nas sociedades capitalistas contemporâneas que seguiram seus rastros. Com a desconsideração do corpo e com a obsessão pela figura do zumbi, por meio das cintilâncias imaginárias, o que quer a sociedade mediática?

\section{Considerações Finais}

Segundo a mitologia grega, ao morrermos, devemos atravessar o rio dos mortos para que nossa alma seja julgada e encaminhada para o lugar certo nos mundos subterrâneos. Esse rio só se atravessa se Caronte, o barqueiro, levar-nos até o outro lado, mas para isso temos de pagar a ele uma moeda de ouro. Se não tivermos essa moeda de ouro, se não atravessarmos o rio na barca de Caronte, estaremos para sempre destinados a perambular pelas margens dos rios dos mortos.

Essa imagem da perambulação pode ser especialmente valiosa para compreendermos o zumbi, esse morto-vivo que devora os cérebros dos vivos e que só morre se o seu próprio cérebro for atingido. Parece que há algo aqui ligado ao cérebro, algo aqui ligado a uma perambulação amaldiçoada, vítima de um feitiço mau.

Nicholas Carr (2011),em uma reflexão acerca dos impactos cognitivos no uso contínuo das tecnologias digitais, e em especial da Internet, conclui sobre ser ela uma tecnologia da distração, que age especificamente promovendo uma crescente dificuldade de concentração da atenção consciente, do foco. Ficamos sem foco, numa espécie de pensamento que perambula inquieto permanentemente, sem demorar em nada tempo suficiente para aprofundamento, ou ainda para sermos de fato afetados em profundidade por qualquer conteúdo. O que nos afeta é o próprio efeito dessa tecnologia sobre nós. 
Esse processo parece ser mais significativo ainda se considerarmos que essa forma de cognição gera o que anteriormente chamamos de rebaixamento da consciência, que pode ser designado por estado hipnógeno (CONTRERA, 2015). Ora, sabemos que a irrupção da consciência em nossa espécie foi justamente o gatilho que nos diferenciou dos demais primatas superiores, bem como a única especificidade que temos, como espécie, entre tantas outras espécies que podem ser consideradas muito mais adaptadas e sincronizadas que nós. Estamos abrindo mão exatamente do que nos diferenciou e nos trouxe até aqui?

Ao falar sobre o impacto cognitivo e na consciência que essa tecnologia gera, Carr (2011) refere-se também a um outro impacto, que acompanha o primeiro: a crescente sedentarização e degeneração das práticas corporais que ativam as cadeias musculares. Os índices oficiais da oms apontam para uma epidemia de obesos e sedentários no mundo, o que também não passou despercebido pela ficção (quem não se lembra da animação Wall-E, de 2008?).

Como resultado temos um corpo em acelerada degeneração e um pensamento perambulando, sem foco. Não vemos melhor metáfora para esse estado de coisas do que o zumbi - sem cérebro, com um corpo morto que se arrasta de lá para cá, em busca de um ininterrupto consumo do que o mantenha no mesmo estado em que está.

Consumo compulsivo (devoração), ansiedade (andar constante), déficit de atenção (hipnogenia, perambulação) são algumas das síndromes que mais lucro dão atualmente aos milionários laboratórios de medicamentos, setor da economia que só perde em enriquecimento para a indústria de armamentos bélicos. Um homem que perambula, que consome ininterruptamente, que rebaixa sua consciência em um estado hipnógeno, como pode ser melhor designado do que por zumbi?

Um homem que namora a morte sob as mais diversas e sub-reptícias maneiras, que pensa intensamente sobre o suicídio, sob qual deus estaria senão sob as asas de Thanatos?

Se é verdade que nos movimentamos por meio de idas e vindas pendulares, neste momento, estamos em um dos extremos desse movimento. Esperamos que o sistema não trave, que o pêndulo não se parta, e que possamos continuar o balanço.

\section{Referências}

BAASLAND, Ernst. Parables and Rhetoric in de the Sermon of the Mont. Turbingen: MohrSiebeck, 2015. 
BAITELLO JUNIOR, Norval. A Era Da

Iconofagia: ensaios de comunicação e cultura. São Paulo: Hakers Editores, 2005.

BAITELLO, N.; SILVA, M. R. Vínculos hipnógenos e vínculos culturais nos ambientes da cultura e da comunicação humana. XXII Compós, Salvador, 2013.

BARROS, ANA. T.M.P. Gilbert Durand, o montanhês que desafiou a margem esquerda do Sena. Revista Esferas. n.4. 2014. Disponível em: <https://portalrevistas.ucb.br/index.php/ esf/article/view/5119/3446> Acessado em: 24 mai. 2018.

BBCa. Diponível em: < http://bbc. in/2tN6RE6>Acessado em: 06 jul. 2017.

Prepared BC. Disponível em: $<$ http://bit. ly/2B4zeS8 >Acessado em: 06 jul. 2017

CAMUS, Albert. O Mito de Sísifo: ensaio sobre o absurdo. Lisboa: Edição Livros do Brasil, 1942.

CAMPBELL, Joseph. O Poder do Mito. São Paulo: Palas Athena, 1990.

CAPONI, Sandra. Uma análise epistemológica do diagnóstico de depressão.

Cadernos Brasileiros de Saúde Mental. v.1 n.1: Florianópolis, 2009. Disponível em: < http:// stat.saudeetransformacao.incubadora.ufsc. br/index.php/cbsm/article/view/1004/1120> Acessado em: 10 abr. 2018.

\section{CARR, N. O que a Internet está Fazendo com} os Nossos Cérebros. São Paulo: 2011.

Casoszumbis. Disponível em: $<$ http://bit. ly/2nx4ZgQ> Acessado em: 06 dez. 2017.

CASTELLS, Manuel. A Sociedade em Rede. São Paulo: Paz e Terra, 2000.
CHEVALIER, J.; GHEERBRANT, A. Dicionário de Símbolos: Mitos, sonhos, costumes, gestos, formas, figuras, cores, números. Rio de Janeiro: José Olimpio, 2017.

CONTRERA, M. Sobre Zumbis, Vampiros e Seres da Cultura Mediática. São Paulo: Revista Líbero, v. 18, n. 36, p. 9-14, jul-dez. 2015.

Mediosfera: meios, imaginários e desencantamento do mundo. 2ed. Porto Alegre: Imaginalis, 2017

.Mídia e Pânico. Saturação da Informação, Violência e Crise Cultural na Mídia. São Paulo: Annablume, Fapesp, 2002. .Mídia e Mimese. In: BORNHAUSEN, D., MIKLOS, J., SILVA, M. R. CISC 20 anos - Comunicação, Cultura e Mídia. São Paulo: CISC; São José do Rio Preto: BLUECOM, 2012. Disponível em: <http://cisc.org.br/portal/ biblioteca/CISC_20_anos-Comunicacao_ Cultura_e_Midia.pdf > Acessado em: 30 out. 2015 .

CONTRERA, M.;ZOVIN, C. Boneca Não Fala - o silêncio mimético na sociedade mediática. Curitiba: Revista Interin, v. 18. n.2. p. 124-136, jul./dez. 2014.

CONTRERA, M.; TORRES, L. Imaginário e Contágio Psíquico. Disponível em: $<$ http:// seer.ufrgs.br/index.php/intexto/article/ view/73671/43474>Acessado em: 22 nov. 2017.

DAVIS, Wade. The Serpent and the Rainbow. Warner Books: New York, 1987.

\section{DENDLE, Peter. The Zombie Movie}

Encyclopedia. McFarland\&Company: North Calfornia, 2001. 
DREZNER, Daniel W. Theories of international politics and zombies. Princeton University Press: New Jersey, 2011.

DURAND, Gilbert. Mito, símbolo e mitodologia. Lisboa: Editorial Presença, 1982. ELIADE, Mircea. O Xamanismo e as Técnicas Arcaicas do Êxtase. São Paulo: Martins Fontes, 2002.

Exame. Disponível em: $<$ http://abr. ai/2su9ExP>Acessado em: 06 jul. 2017.

EUA Zumbi.<https://bit.ly/2yjJAwR $>$ Acessado em: 13 jun. 2018.

Felicia. Disponível em: $<$ http://bit. ly/2viSyED>Acessado em: 24 ago. 2017.

FOSTER, G. A. Hoarders, Doomsday Preppers, and the Culture of Apocalypse. Nova York: MacMillan, 2014.

Filmow. Disponível < http://bit.ly/2BL205c > Acessado em: 7 dez. 2017.

Google Trends. Disponível em: $<$ https://bit. ly/2IJwHwK> Acessado em: 09 fev. 2018. . Disponível em: $<$ https://bit.ly/2DYY4j7> Acessado em: 27 mar. 2018a.

GONZALO, Jorge. F. Filosofía Zombi.

Barcelona: Anagrama, 2011.

GUIMARÃES, Marília Z. P. o Crack e o Abuso de Drogas. Disponível em: <http://nupevi.iesp. uerj.br/artigos/crack_abuso.pdf $>$ Acessado em: 22 mai. 2018.

HANDERSON, Joseph. Vodu no Haiti Candomblé no Brasil: identidades culturais e sistemas religiosos como concepções de mundo Afro-Latino-Americano / Joseph Handerson ; Orientador : Beatriz Ana Loner. Pelotas, 2010.
HARARI, N. H. Uma Breve História da Humanidade Sapiens. Porto Alegre: L\&PM, 2015.

HILLMAN, J. Cidade \& Alma. São Paulo: Studio Nobel, 1993.

.Paranoia. Petrópolis: Vozes, 2016.

Hypescience. Disponível em: <http://bit. ly/2suw4z2 > Acessado em: 06 jul. 2017.

Ibope. Disponível em: < http://bit. ly/2k4WwKT>Acessado em: 06 dez. 2017.

Imdb. Disponível em: < http://www.imdb.com/ title/tt1386697/> Acessado em: 27 mar. 2018.

JUNG, C. G. A Natureza da Psique. Disponível em: $<$ http://bit.ly/2BfWXeS $>$ Acessado em: 22 nov. 2017.

.Aspectos do drama contemporâneo. Petrópolis: Vozes, 2011 .

.O Homem e Seus Símbolos. Rio de Janeiro: Nova Fronteira, 2008.

AION - Estudos Sobre o Simbolismo do Si-Mesmo. Petrópolis: Editora Vozes, 1982. .Interpretação Psicológica do Dogma da Trindade. Petrópolis: Editora Vozes, 2012. . E Eu e o Inconsciente. Petrópolis: Vozes, $2011 b$.

.Respostas a Jó. Editora Vozes: Petrópolis, 1986.

.Símbolos da Transformação. Editora Vozes. Petrópolis, 1995.

Jogo do ano. Disponível em: <http://bit. ly/2AoNNVj>Acessado em: 22 nov. 2017.

KAMPER, D. O Trabalho Como Vida. Ana Blume: São Paulo, 1998. 
.Corpo. Disponível em: $<$ http://bit.

ly/2sKT692 >. Acessado em: 10 de set de 2015 .

KELEMAN, S; CAMPBELL, J. Mito e Corpo. São Paulo: 2001.

Krokodil. < https://bit.ly/2Mirxow> Acessado em: 16 jun. 2018.

LEROI-GOURHAN, André. As Religiões da

Pré-História. Lisboa: Edições 70, 2007.

Letargia. Disponível em: <https://www.dicio. com.br/letargia/>Acessado em: $06 \mathrm{dez} .2017$.

LORENZ, K. Oito Pecados da Civilização.

Editora Humana, 2009.

MACLEAN, P. D. The triune brain in evolution

- Role in paleocerebral functions. New York:

Plenum Press, 1990.

Meeker. Disponível em: <http://www.

kpcb.com/internet-trends $>$ Acessado em:

06 dez. 2017.

MOGRABI. Considerações sobre a teoria do cérebro triuno e sua relevância para uma filosofia da mente e das emoções. Revista Veritas. v. 60, n. 2. Ano 2005. Disponível em: $<$ https://bit.ly/2IDTnCK> Acessado em: 23 de mai. 2018.

MONOD, J. Leçon inaugurale au Collège de France. Nogent-le-Rotrou, Doupelay Gouverneur, 1968.

MORIN, Edgar.Cultura de Massas no Século

XX. Rio de Janeiro: Forense-Universitária, 1997.

.O Homem e a Morte. Rio de Janeiro, Zahar, 1979.

.O método IV - As Ideias: habitat, vida costumes, organização. Trad. Juremir Machado da Silva. 5aed. Porto Alegre:

Sulina. 2011.
.O método V: A Humanidade da

Humanidade: a identidade humana. Trad. Juremir Machado da Silva. 5aed. Porto Alegre: Sulina. 2012

.o Enigma do homem: para uma nova antropologia. Rio de Janeiro, Zahar, 1975.

Introdução ao pensamento complexo.

Trad. Eliane Lisboa. Porto Alegre: Sulina. 2005 b.

Newzoo. Disponível em: <http://bit.

ly/2cD62XZ> Acessado em: 06 dez. 2017.

NICOLÓSI, Regina. H. O. S. Naturalidade Sem Natureza: a construção da mulher como simulacro na Revista Plástica \& Beleza. São Paulo: UNIP, 2018.

Noite sinistra. Disponível em: $<$ http://bit. ly/2uOHxKt>Acessado em: 06 jul. 2017.

Oxford. Disponível em: $<$ http://bit. ly/2tucQuN>Acessado em: 06. jul. 2017.

PIERUCCI, Flávio. Desencantamento do mundo: Todos os passos do conceito de Max Weber. São Paulo: Ed. 34, 2013.

POPPER, K.; ECCLES, J. The Self and its Brains. Nova Iorque: Springer-Verlag, 1977.

Prêmios Walking Dead. Disponível em: $<$ http://bit.ly/2suiVQl>Acessado em: 06 jul. 2017.

RE. Disponível em: <http://bit.ly/2AD9PvS> Acessado em: 06 dez. 2017.

SEIFTER, Ari; SCHWARZWALDER, Alison, GEIS, Kate; AUCOTT, John. The utility of "Google Trends" for epidemiological research: Lymedisease as an example. Revista Geospatial Health. V. 4(2). pp.135-137. Estados Unidos: 2010. Disponível em:< http://www. 
geospatialhealth.net/index.php/gh/article/

view/195> Acessado em: 06 fev. 2018.

SQUAD, Suicide. Direção: David Ayer.

Produção: Charles Roven, Richard Suckle.

Estados Unidos da América: Warner Bros

Pictures, 2016.

SMITH, Caleb. The Evolution of Protagonist-

Zombie Interactions in American Zombie

Cinema: A Mirror of Evolving Race Relations

Between White and Black America.

Disponível em:<http://bit.ly/2EvrYzO>

Acessado em: 09 fev. 2018.

SODRÉ, M. Antropológica do espelho: uma

teoria da comunicação linear e em rede.

Petrópolis/RJ: Vozes, 2013.

Steam. Disponível em: $<$ http://bit.

ly/2EecTj3>Acessado em: 09 de fev. 2018.

Stevecutts. <http://www.stevecutts.

com/>Acessado em: 22 de nov. 2017.

SuicidioBrasil. Disponível em: <http://

portalarquivos.saude.gov.br/images/pdf/2017/

setembro/21/Coletiva-suicidio-21-09.pdf>

Acessado em: 27 mar. 2018.

TORRES, Leonardo. Do Devaneio à Sedação

da Luz. IX ABCiber. Disponível em: <http://bit.

ly/2jOp8oa>Acessado em: 22 nov. 2017.

Unifesp. Disponível em: <http://bit.ly/2iZ8x9Q $>$ Acessado em: 06 jul. 2017.

Urbandic. Disponível em: $<$ http://bit. ly/2tuJYCw>Acessado em: 06 jul. 2017.

WALL-E. Direção: Andrew Stanton. Produção: Jim Morris. 98 min. DVD. Col. Walt Disney Studios, 2008. 


\section{THE ZOMBIE IN THE MEDIATIC IMAGINARY: Zombie and Death Pulsion in the Media Society}

\section{Abstract}

The article aimst symbolic irruption in the electronic media of the zombie figure and aims to analyze what it represents in the cultural and media imaginary. The question posed is whether the zombie would be a metaphor for some current human question. As a method, we map zombie recurrence through quantitative Google Trends data. From this, we perform a qualitative analysis of media products (serials, films, games and news) in order to highlight the cultural context in which the zombie symbolically manifests itself. The proposed theoretical discussion used the contributions of E. Morin, G. Durand, A. T. Portanova Barros, C. G. Jung and J. Gonzalo.

\section{Keywords}

Media Imaginary. Death. Zombie.

\section{EL ZOMBIE EN LA IMAGINACIÓN DE LOS MEDIOS: Zombie e Impulso de Muerte en la Sociedad de los Medios}

\section{Resumen}

El artículo tiene como objeto la irrupción simbólica en los medios de comunicación electrónicos de la figura del zumbi y tiene como objetivo analizarlo que ella representa en el imaginario cultural y mediático. La pregunta que propone es la de si el zumbi sería metáfora de alguna cuestión humana actual. Como método, mapeamos la recurrencia del zumbi a través de datos cuantitativos de Google Trends. A partir de eso, realizamos análisis cualitativo de productos mediáticos (series, películas, juegos y noticias), a fin de evidenciar el contexto cultural e nel que el zombi se manifiesta simbólicamente. La discusión teórica propu esta utilizó las contribuciones de E. Morin, G. Durand, A. T. Portanova Barros, G. Jung y J. Gonzalo.

\section{Palabras clave}

Imaginario Mediatico. La muerte. Zombi.

\section{Malena Segura Contrera}

Doutora em Comunicação e Semiótica pela Pontifícia Universidade Católica de São Paulo e professora titular do Curso de Mestrado em Comunicação da Universidade Paulista de São Paulo. Email: malenacontrera@uol.com.br ORCID: http://orcid.org/0000-0003-4334-9467

\section{Leonardo Torres}

Doutorando em Comunicação e Cultura Midiática da Universidade Paulista de São Paulo. Email: leosouzatorres@gmail.com ORCID: https://orcid.org/0000-0002-0511-8775
Concepção e desenho do estudo:

Malena Contrera e Leonardo Torres

Aquisição, análise ou interpretação dos dados:

Leonardo Torres

Redação do manuscrito:

Malena Contrera e Leonardo Torres

Revisão crítica do conteúdo intelectual: Malena Contrera 